\title{
INFLUÊNCIA DO TEOR DE NITROGÊNIO NO CULTIVO DE Spirulina maxima EM DUAS TEMPERATURAS - Parte I: ALTERAÇÃO DA COMPOSIÇÃO DA BIOMASSA ${ }^{1}$
}

\author{
Gilvair Marconi dos SANTOS ${ }^{2}$, Ricardo Verthein Tavares de MACEDO ${ }^{3, *}$, Ranulfo Monte ALEGRE ${ }^{3}$
}

\begin{abstract}
RESUMO
Spirulina maxima é uma cianobactéria de grande interesse para a produção de substâncias nutritivas e terapêuticas. É mesofilica, essencialmente fotoautotrófica, sendo suas principais fontes de nitrogênio os nitratos, uréia ou sais de amônio em meios com alta alcalinidade [1, $2,3,10,16]$. Spirulina maxima foi cultivada em fermentadores, expostos a luz com intensidade de 24001 ux, contendo $3 \mathrm{~L}$ do meio proposto por PAOLETTI, PUSHPARAJ \& TOMASELLI [7] com concentração de $2,5 \mathrm{~g} / \mathrm{L}$ de $\mathrm{KNO}_{3}$, em meio modificado com 0 ,2g/L de KNO ${ }_{3}$ e em meio sem fonte de nitrogênio, denominados respectivamente meios 2,5N,0,2N e SN, visando observar as alterações provocadas em sua composição final. Em culturas crescidas a $35^{\circ} \mathrm{C}$ observou-se redução do teor de proteinas na massa celular seca de $28,84 \%$ e de $32,87 \%$, aumento do teor de carboidratos de $30,34 \%$ e de $54,21 \%$ e aumento dos lipídios totais de $287,90 \%$ e $277,37 \%$, quando se utilizou os meios $0,2 \mathrm{~N}$ e $\mathrm{SN}$, respectivamente, em comparação com o meio 2,5N. O teor de cinzas mostrou variação desprezivel. Quando a temperatura de cultivo foi reduzida para $25^{\circ} \mathrm{C}$, ocorreu uma redução do teor de proteínas da massa seca de 40,28\% e 39,02\%, aumento de teor de carboidratos de $88,90 \%$ e de $91,15 \%$ e aumento do teor de lipídios totais em $321,25 \%$ e de $307,08 \%$, quando se utilizou os meios 0 ,2N e SN em comparação com o meio 2,5N, respectivamente. Os resultados mostraram alterações sensiveis na composição da biomassa seca, com a diminuição do teor de nitrogênio e da temperatura de cultivo, exceto no teor de cinzas que não foi significativo.

Palavras-chave: Spirulina; biomassa; microalga; composição centesimal.
\end{abstract}

\section{SUMMARY}

INFLUENCE OF NITROGEN CONCENTRATION ON THE CULTURE OF Spirulina maxima GROWN AT TWO TEMPERATURES - Part I: CHANGES IN BIOMASS COMPOSITION. Spirulina maxima is a cianobacter of great interest to the production of nutritious and therapeutic substances. It is mesophilic, essentially fotoautotrophic and has preference for media with high alkalinity. Its principal nitrogen source are nitrates and ammonium salts or urea $[1,2,3,10,16]$. Spirulina maxima was cultured in fermentors with 3 liters of medium proposed by PAOLETTI, PUSHPARAJ \& TOMASELLI [7] exposed at light with intensity of 2400lux and in two other media in which the $\mathrm{KNO}_{3}$ concentration was reduced from 2.5 to $0.2 \mathrm{~g} / \mathrm{L} \mathrm{KNO}_{3}$ and zero, that were denominated $2.5 \mathrm{~N}$ and $0.2 \mathrm{~N}$ and medium without $\mathrm{KNO}_{3} \mathrm{SN}_{3}$ respectively. In cultures at $35^{\circ} \mathrm{C}$ a reduction of the percentage of proteins was observed, in the dry cellular mass, of $28.84 \%$ and $32.87 \%$, an increased of $30.34 \%$ and of $54.21 \%$ in carbohydrates and total lipids of $287.90 \%$ and $277.37 \%$, when it was used the media $0.2 \mathrm{~N}$ and SN instead the medium $2.5 \mathrm{~N}$ respectively, except the percentage of ashes that showed no significant variation. When the temperature was reduced from 35 to $25^{\circ} \mathrm{C}$, the percentage of protein in the dry mass decreased $40.28 \%$ and $39.02 \%$, while the percentage of carbohydrates increased $88.9 \%$ and of $91.15 \%$ and percentage of total lipidic increased $321.25 \%$ and of $307.08 \%$, when it was used the media $0.2 \mathrm{~N}$ and $\mathrm{SN}$ instead of the medium $2.5 \mathrm{~N}$ respectively. The percentage of ashes showed no significant variation. The data showed a sensitive alteration in the cellular mass composition when the percentage of nitrogen and the cultivation temperature were decreased. Keywords: Spirulina; biomass; microalgae; centesimal composition.

\section{1 - INTRODUÇÃO}

Spirulina maxima é uma cianobactéria que pode ser utilizada na composição de alimentos dietéticos e tem sido objeto de estudos em vários países como Israel, Japão, França, E.U.A. e Brasil [2,3]. Juntamente com outras microalgas, podem ser utilizadas como fonte alternativa de proteínas, lipídios (ácidos graxos essenciais), ficocianina e outros, em alimentos e rações. Desenvolve-se bem na faixa de temperatura de 35 a $37^{\circ} \mathrm{C}$, é essencialmente fotoautotrófica, tem preferência por meios alcalinos, com $\mathrm{pH}$ na faixa de 8,5 a 11 , sendo sensivel a mudanças bruscas no seu meio de cultivo $[1,2,5,9,10,15]$. Spirulina maxima apresenta altas concentrações de proteínas de fácil digestão e contém todos os aminoácidos essenciais em concentrações acima do padrão alimentar da FAO-OMS, com valor de PER

1. Recebido para publicação em 19/03/2001. Aceito para publicação em 16/05/2002 (000605).

${ }^{2}$ Departamento de Tecnologia de Alimentos/UFRRJ, Seropédica - RJ, $B R, C E P$ 23. 851-970

3. Departamento de Engenharia de Alimentos/UNICAMP, Campinas - SP, BR, CEP 13.081-970.

* A quem a correspondência deve ser enviada.
(Razão de eficiência protéica) de 2,2, acima do valor de outras fontes, mostrando a importância da sua utilização como alimento em futuro próximo $[4,5,10]$.

Segundo PAOLETTI, VICENZI \& BOCCI [8] Spirulina maxima apresentou em sua composição centesimal 72 , 12 e $11 \%$ de proteinas, lipídios e carboidratos respectivamente, quando cultivada em laboratório. Porém, estes valores alteraram-se para 60, 15 e 16\% respectivamente, quando o cultivo foi feito em tanque aberto, o que mostrou que a composição das algas pode alterar em função da maneira como esta é cultivada.

Foi observado que o conteúdo de lipídios de algas verdes aumentou de duas a três vezes após 5 a 9 dias em meio com ausência de nitrogênio e que a presença de nitrato, fosfato e bicarbonato em baixas concentrações promoveu um aumento significativo da fração de carboidratos e proteínas nas células, acompanhado de aumento da concentração de cloreto de sódio [3, 11, 12, 13].

Em relação à temperatura de cultivo, observa-se que a variação de $30^{\circ} \mathrm{C}$ para $42^{\circ} \mathrm{C}$ promoveu um aumento de $7,4 \%$ para $11,5 \%$ no conteúdo de lipídios, um decréscimo de $58,6 \%$ para $45 \%$ do conteúdo de proteínas e um aumento de $29,9 \%$ para $38,7 \%$ do conteúdo de carboidratos [13]. 
A variação da composição centesimal de Spirulina maxima em função das condições de cultivo e composição do meio fazem dela uma boa opção para a produção de biomassa alimentar, principalmente em regiões áridas com radiação solar intensa, pois, além de suportar temperaturas relativamente elevadas, pode ser cultivada em águas com alta salinidade [4, 12].

\section{2 - MATERIAL E MÉTODOS}

\section{1 - Microrganismo}

A cepa de Spirulina maxima utilizada neste trabalho era predominantemente reta, não axênica, foi cedida pelo laboratório de fermentações do Departamento de Tecnologia de Alimentos da UFRRJ.

\section{2 - Condições de manutenção da cepa}

A manutenção da cepa foi feita em Erlenmeyers de $1000 \mathrm{~mL}$, com $200 \mathrm{~mL}$ do meio de cultivo, com a seguinte composição em g/L, proposto por PAOLETTI, PUSHPARAJ \& TOMASELLI [7]: $\mathrm{KNO}_{3}, 2,5 ; \mathrm{NaHCO}_{3}, 15,15 ; \mathrm{Na}_{2} \mathrm{CO}_{3}$, 8,$9 ; \mathrm{K}_{2} \mathrm{SO}_{4}, 1,9 ; \mathrm{K}_{2} \mathrm{HPO}_{4}, 0,5 ; \mathrm{NaCl}, 0,92 ; \mathrm{MgSO}_{4} .7 \mathrm{H}_{2} \mathrm{O}$, 0,$25 ; \mathrm{CaCl}_{2} \cdot 2 \mathrm{H}_{2} \mathrm{O}, 0,05$ e $1 \mathrm{~mL}$ de solução de micronutrientes, com a seguinte composição em g/L: $\mathrm{H}_{3} \mathrm{BO}_{3}, 2,86 ; \mathrm{MnCl}_{2} \cdot 4 \mathrm{H}_{2} \mathrm{O}, 1,81 ; \mathrm{ZnSO}_{4} .7 \mathrm{H}_{2} \mathrm{O}, 0,22$; $\mathrm{Na}_{2} \mathrm{Mo}_{2} \mathrm{O}_{4} \cdot 2 \mathrm{H}_{2} \mathrm{O}, 0,39 ; \mathrm{CaSO}_{4} \cdot 5 \mathrm{H}_{2} \mathrm{O}, 0,079 ; \mathrm{Co}\left(\mathrm{NO}_{3}\right)_{2} \cdot 6 \mathrm{H}_{2} \mathrm{O}$, 0,049 e Fe.EDTA $1 \mathrm{~mL}$ de solução; de EDTA. Na 29,8g/L; $\mathrm{FeSO}_{4} \cdot 7 \mathrm{H}_{2} \mathrm{O}$ e $\mathrm{H}_{2} \mathrm{O}$ p/ $1000 \mathrm{~mL}$.

As culturas foram mantidas à temperatura ambiente $\left(26^{\circ} \mathrm{C}\right)$ sob iluminação de duas lâmpadas fluorescentes de $40 \mathrm{~W}$, sendo feitos repiques mensais.

\section{3 - Obtenção da biomassa}

O meio proposto por PAOLETTI, PUSHPARAJ \& TOMASELLI [7] foi denominado meio $2,5 \mathrm{~N}$ e, além desse, foram usados para a obtenção da biomassa mais dois outros meios para o crescimento, um com concentração de $\mathrm{KNO}_{3}$ de $0,2 \mathrm{~g} / \mathrm{L}$, denominado de meio $0,2 \mathrm{~N}$, e outro sem a presença desse sal, denominado de meio SN. O $\mathrm{pH}$ inicial foi ajustado em 9,5 e foram feitos cultivos a $25^{\circ} \mathrm{C}$ e $35^{\circ} \mathrm{C}$, temperaturas que representam as médias das isotermas climáticas brasileiras, de acordo com informações climatológicas da EMBRAPA, CNPAB/RJ.

$O$ crescimento foi feito em fermentadores com $3000 \mathrm{~mL}$ de meio cada, aos quais adicionou-se um volume da cultura de manutenção correspondente a 100mg/ L de massa celular seca, por 10 dias, sob iluminação de seis lâmpadas florescentes de 40W cada.

A biomassa obtida na forma de gel, foi filtrada à vácuo sobre peneira com malha de $44 \mu \mathrm{m}$, sendo lavada com solução salina para a retirada do excesso de carbonatos. A biomassa foi seca a $95^{\circ} \mathrm{C}$ até peso constante e as análises da composição centesimal feitas segundo a metodologia de análise de alimentos [6], sendo a percentagem de carboidratos determinada pela diferença entre e as percentagens dos demais componentes analisados em base seca. Os resultados das percentagens para proteinas foram avaliados estatisticamente pela metodologia de superficie de resposta, utilizando o software STATISTICA.

\section{3 - RESULTADOS E DISCUSSÃO}

As Figuras 1 e 2 representam as curvas de crescimento da Spirulina maxima em função do tempo, para os três meios utilizados nas temperaturas de $35^{\circ} \mathrm{C}$ e $25^{\circ} \mathrm{C}$ respectivamente.

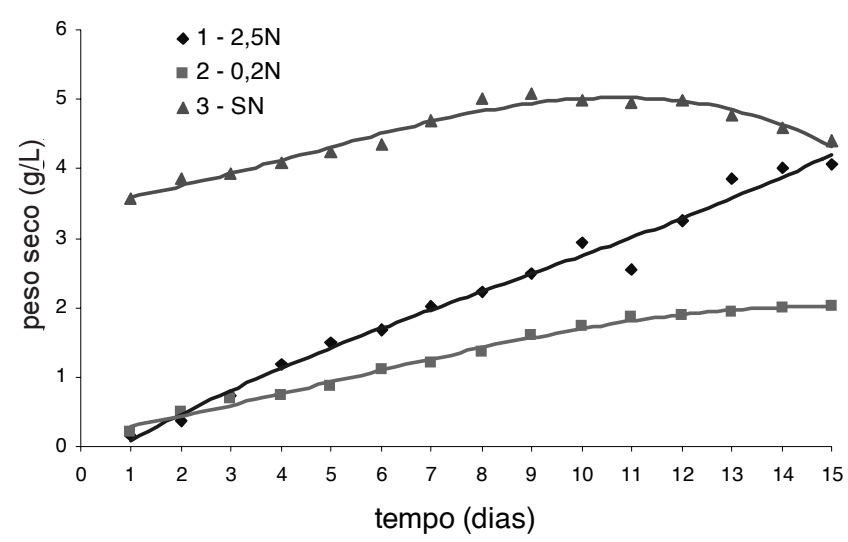

FIGURA 1. Crescimento a $35^{\circ} \mathrm{C}$, nos meios $2,5 \mathrm{~N}, 0,2 \mathrm{~N}$ e SN.

Observou-se que para cada meio as curvas de crescimento a $35^{\circ} \mathrm{C}$ e a $25^{\circ} \mathrm{C}$ apresentaram comportamentos semelhantes, com a produção de massa seca pouco maior a $35^{\circ} \mathrm{C}$, exceto para o meio $0,2 \mathrm{~N}$ que em 15 dias produziu o dobro do mesmo crescimento a $25^{\circ} \mathrm{C}$, apresentando ainda uma descoloração devido à utilização das biliproteínas como a ficocianina, conforme já observado por outros autores.

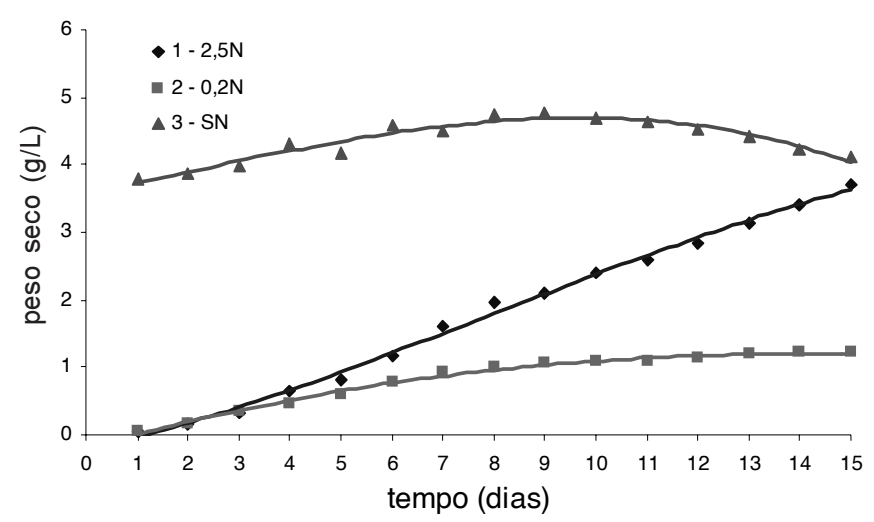

FIGURA 2. Crescimento a $25^{\circ} \mathrm{C}$, nos meios $2,5 \mathrm{~N}, 0,2 \mathrm{~N}$ e SN.

A curva 3 , em $35^{\circ} \mathrm{C}$ e $25^{\circ} \mathrm{C}$ para o meio SN, está em um patamar mais alto devido ao crescimento neste meio sem nitrogênio iniciar após o pleno crescimento em outro meio $2,5 \mathrm{~N}$. 
Conforme mostra a Tabela 1, para a composição da biomassa seca a $35^{\circ} \mathrm{C}$, observou-se que com a diminuição do $\mathrm{KNO}_{3}$ do meio $2,5 \mathrm{~N}$ para o meio $0,2 \mathrm{~N}$ houve uma diminuição de $28,84 \%$ do teor protéico, um aumento de $30,34 \%$ do teor de carboidratos e um aumento de $287,90 \%$ do teor de lipídios.

Do meio $2,5 \mathrm{~N}$ para o meio $\mathrm{SN}$ houve uma diminuição de $32,87 \%$ do teor protéico, um aumento de 54,21\% do teor de carboidratos e um aumento de $277,37 \%$ do teor de lipidios.

Comparando-se os teores do meio 0,2N para os do meio SN houve uma pequena variação, com uma diminuição de 5,65\% do teor de proteína, uma redução de $3,66 \%$ do teor de lipídios e um aumento de $18,31 \%$ do teor de carboidratos.

TABELA 1. Composição centesimal da biomassa seca a $35^{\circ} \mathrm{C}$.

\begin{tabular}{|c|c|c|c|c|c|c|}
\hline $\mathrm{T}$ & $\mathrm{N}$ & rep. & PROTEÍNAS & CINZAS & CARBOIDRATOS & LIPÍDIOS \\
\hline${ }^{\circ} \mathrm{C}$ & $g / L$ & & $\%$ & $\%$ & $\%$ & \\
\hline 35 & 2,5 & 1 & 68,42 & 7,6 & 16,03 & 7,95 \\
\hline 35 & 2,5 & 2 & 71,02 & 5,84 & 14,92 & 8,22 \\
\hline 35 & 2,5 & 3 & 71,81 & 5,77 & 13,54 & 8,88 \\
\hline \multicolumn{3}{|c|}{ Média } & 70,42 & 6,40 & 14,83 & 8,35 \\
\hline \multicolumn{3}{|c|}{ Desvio padrão } & 1,77 & 1,04 & 1,25 & 0,48 \\
\hline 35 & 0,2 & 1 & 53,28 & 5,76 & 18,18 & 22,78 \\
\hline 35 & 0,2 & 2 & 52,46 & 5,58 & 17,65 & 24,31 \\
\hline 35 & 0,2 & 3 & 44,56 & 8,25 & 22,15 & 25,04 \\
\hline \multicolumn{3}{|c|}{ Média } & 50,1 & 6,53 & 19,33 & 24,04 \\
\hline \multicolumn{3}{|c|}{ Desvio padrão } & 4,82 & 1,49 & 2,46 & 1,15 \\
\hline 35 & 0 & 1 & 44,48 & 6,23 & 26,03 & 23,26 \\
\hline 35 & 0 & 2 & 49,13 & 7,09 & 21,09 & 22,69 \\
\hline 35 & 0 & 3 & 48,19 & 6,81 & 21,48 & 23,52 \\
\hline \multicolumn{3}{|c|}{ Média } & 47,27 & 6,71 & 22,87 & 23,16 \\
\hline \multicolumn{3}{|c|}{ Desvio padrão } & 2,46 & 0,44 & 2,75 & 0,42 \\
\hline
\end{tabular}

A Tabela 2 mostra a composição a $25^{\circ} \mathrm{C}$ da biomassa seca, onde observou-se um comportamento semelhante ao obtido a $35^{\circ} \mathrm{C}$ do meio $2,5 \mathrm{~N}$ para o meio $0,2 \mathrm{~N}$, com uma diminuição de 40,28\% do teor protéico, um aumento de $88,90 \%$ do teor de carboidratos e um aumento de $321,25 \%$ do teor de lipídios.

TABELA 2. Composição centesimal da biomassa seca a $25^{\circ} \mathrm{C}$.

\begin{tabular}{|c|c|c|c|c|c|c|}
\hline $\mathrm{T}$ & $\mathrm{N}$ & rep. & PROTEÍNAS & CINZAS & CARBOIDRATOS & LIPÍDIOS \\
\hline${ }^{\circ} \mathrm{C}$ & $g / L$ & & $\%$ & $\%$ & $\%$ & $\%$ \\
\hline 25 & 2,5 & 1 & 70,74 & 7,34 & 14,98 & 6,94 \\
\hline 25 & 2,5 & 2 & 72,33 & 6,52 & 14,88 & 6,27 \\
\hline 25 & 2,5 & 3 & 71,19 & 6,96 & 12,87 & 7,98 \\
\hline \multicolumn{3}{|c|}{ Média } & 71,42 & 6,94 & 14,24 & 7,06 \\
\hline \multicolumn{3}{|c|}{ Desvio padrão } & 0,82 & 0,41 & 1,19 & 0,86 \\
\hline 25 & 0,2 & 1 & 41,64 & 8,12 & 27,36 & 22,88 \\
\hline 25 & 0,2 & 2 & 42,92 & 7,38 & 26,54 & 23,16 \\
\hline 25 & 0,2 & 3 & 43,38 & 7,84 & 26,79 & 21,99 \\
\hline \multicolumn{3}{|c|}{ Média } & 42,65 & 7,78 & 26,90 & 22,68 \\
\hline \multicolumn{3}{|c|}{ Desvio padrão } & 0,90 & 0,37 & 0,42 & 0,61 \\
\hline 25 & 0 & 1 & 44,74 & 6,65 & 26,56 & 22,35 \\
\hline 25 & 0 & 2 & 44,81 & 7,39 & 25,96 & 21,84 \\
\hline 25 & 0 & 3 & 41,09 & 8,91 & 29,15 & 20,85 \\
\hline \multicolumn{3}{|c|}{ Média } & 43,55 & 7,65 & 27,22 & 21,68 \\
\hline \multicolumn{3}{|c|}{ Desvio padrão } & 2,13 & 1,15 & 1,70 & 0,76 \\
\hline
\end{tabular}

Do meio $2,5 \mathrm{~N}$ para o meio $\mathrm{SN}$ houve uma diminuição de 39,02\% do teor protéico, um aumento de $91,15 \%$ do teor de carboidratos e um aumento de $307,08 \%$ do teor de lipidios.

Comparando-se os teores do meio $0,2 \mathrm{~N}$ para o meio SN houve também uma pequena variação, com redução de $2,11 \%$ do teor de proteínas, redução de 4,41\% do teor de lipídios e aumento de $1,19 \%$ do teor de carboidratos.

O teor de cinzas mostrou pouca alteração, com aumento de $2,03 \%$ e $4,84 \%$ a $35^{\circ} \mathrm{C}$ e $12,10 \%$ e $10,23 \%$ a $25^{\circ} \mathrm{C}$, do meio $2,5 \mathrm{~N}$ para os meios $0,2 \mathrm{~N}$ e $\mathrm{SN}$ respectivamente, sendo que os valores iniciais para o meio $2,5 \mathrm{~N}$ a $35^{\circ} \mathrm{C}$ encontrados estão de acordo com os citados por PAOLETTI, VICENZI \& BOCCI [8], de 4 a $6 \%$, e por TORRES [14], de 8,1\%.

Os resultados mostraram que a temperatura de cultivo não teve tão grande influência na composição da biomassa como as que ocorreram com a redução do teor de nitrogênio. Para o meio $2,5 \mathrm{~N}$ a $35^{\circ} \mathrm{C}$, o valor médio inicial de $70,42 \%$ de proteínas estão de acordo com os citados, de $68,5 \%$ a $77 \%$, por PAOLETTI, VICENZI \& BOCCI [8] e TORRES [14].

Para a variação da temperatura, de $35^{\circ} \mathrm{C}$ para $25^{\circ} \mathrm{C}$, proteínas mostraram um aumento de $1,42 \%$ para o meio $2,5 \mathrm{~N}$, uma diminuição de $14,87 \%$ para o meio $0,2 \mathrm{~N}$ e uma diminuição de $7,87 \%$ para o meio SN. Os lipídios totais mostraram uma diminuição de $15,45 \%$ para o meio $2,5 \mathrm{~N}$, de $5,66 \%$ para o meio $0,2 \mathrm{~N}$ e de $6,39 \%$ para o meio SN. Carboidratos mostraram uma diminuição de 3,98\% para o meio $2,5 \mathrm{~N}$, um aumento de $39,16 \%$ para o meio $0,2 \mathrm{~N}$ e de $19,02 \%$ para o meio SN. Os teores iniciais de carboidratos a $35^{\circ} \mathrm{C}$, para o meio $2,5 \mathrm{~N}$, são compativeis com os valores de até $20 \%$ para Spirulina platensis, citados por PAOLETTI, VICENZI \& BOCCI [8] e de até 16\% para Spirulina maxima, $[8,9,14]$.

TABELA 3. Parâmetros para superfície de resposta.

\begin{tabular}{lccc}
\hline & $\mathrm{A}$ & $\mathrm{B}$ & $\mathrm{C}$ \\
\hline Estimate & 35,63835 & 0,582237 & 4,01801 \\
Std.Err. & 4,09336 & 0,114471 & 0,23863 \\
$\mathrm{t}(15)$ & 8,70638 & 5,086336 & 16,83809 \\
p-level & 0,00000 & 0,000134 & 0,00000
\end{tabular}

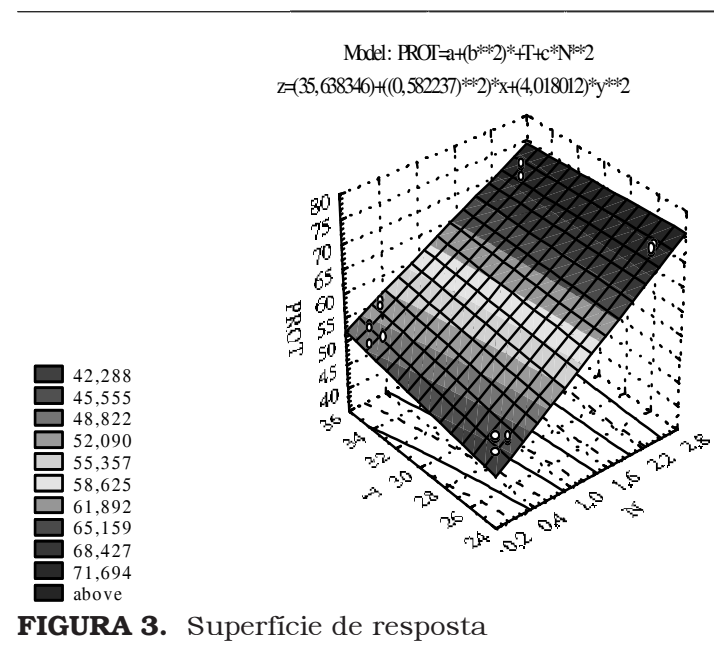

Na Tabela 3, PROTEÍNAS mostrou valores do desvio padrão maiores do que uma ordem de grandeza dos valores dos parâmetros, o teste $\mathrm{t}$ mostrou aproximadamente 
3 vezes o valor mínimo necessário para $B$, o nivel $\mathrm{p}$ mostrou praticamente não haver erro entre os parâmetros, com valores muito menores do que $5 \%$. A função mostrou excelente relação com os valores experimentais, apresentando um coeficiente de correlação $\mathrm{R}=0,97505$.

A Figura 3 mostra a superficie de resposta dos parâmetros, PROTEÍNAS, TEMPERATURA e NITROGÊNIO.

A função proposta mostrou para a variação de proteínas, nas condições limitantes de nitrogênio e de temperatura estudadas, uma boa aproximação com os resultados experimentais com a seguinte equação: PROT $=\mathrm{A}+\mathrm{B}^{2} \mathrm{~T}+\mathrm{CN}^{2}$.

A Tabela 4 mostra que a correlação entre os parâmetros, valores previstos versus valores observados, apresentou pouca dispersão entre os resultados.

O gráfico da Figura 4 mostra pouca dispersão entre os valores de resultados previstos e resultados observados.

TABELA 4. Matriz de correlação dos parâmetros estimados.

\begin{tabular}{cccc}
\hline & A & B & C \\
\hline A & 1,000000 & $-0,977624$ & $-0,122227$ \\
B & $-0,977624$ & 1,000000 & 0,000000 \\
C & $-0,122227$ & 0,000000 & 1,000000 \\
\hline
\end{tabular}

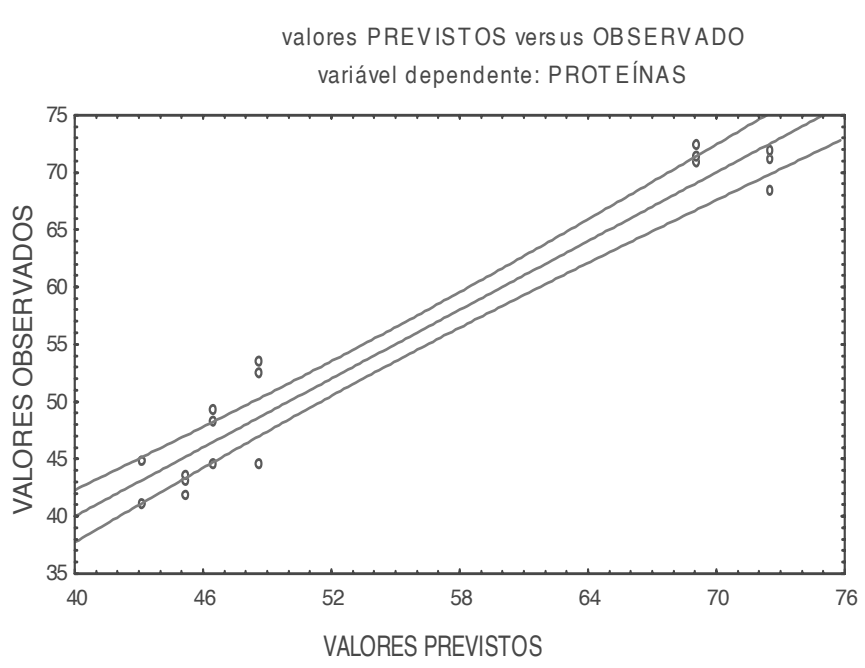

FIGURA 4. Parâmetros estimados

\section{4 - CONCLUSÕES}

Foi observado que houve uma sensivel alteração na composição centesimal da Spirulina maxima quando se alterou o teor de nitrogênio e a temperatura do seu meio de cultivo.

Houve diminuição de $28 \%$ a $32 \%$ a $35^{\circ} \mathrm{C}$ e $40 \%$ a $39 \%$ a $25^{\circ} \mathrm{C}$ aproximadamente nas concentrações de proteinas, predominantemente com a diminuição de N, de $2,5 \mathrm{~g} / \mathrm{L}$ para $0,2 \mathrm{~g} / \mathrm{L} \mathrm{KNO}_{3}$ e para ausência de nitrogênio no seu meio de cultivo, em relação à diminuição da temperatura, de $35^{\circ} \mathrm{C}$ para $25^{\circ} \mathrm{C}$ respectivamente, confirmando citações anteriores.

Pode-se deduzir que os componentes nitrogenados transformaram-se em substâncias de reserva energética, como carboidratos, que apresentaram aumentos de $30 \%$ a $54 \%$ a $35^{\circ} \mathrm{C}$ e $88 \%$ a $91 \%$ a $25^{\circ} \mathrm{C}$ e lipidios, que apresentaram aumentos de $288 \%$ a $277 \%$ a $35^{\circ} \mathrm{C}$ e $321 \%$ a $307 \%$ a $25^{\circ} \mathrm{C}$ respectivamente, quando se submeteu a Spirulina maxima às condições apresentadas anteriormente.

Deduz-se portanto serem estas alterações oportunas para a aplicação em um sistema de produção de algumas substâncias de interesse produzidas por esta microalga, em maior escala e de uma forma econômica, como lipídios por exemplo.

\section{5 - REFERÊNCIAS BIBLIOGRÁFICAS}

[1] BOROWITZKA, M. A. Algal biotechnology products and processes-matching science and economics. Appyied Phycology, v.4, n.3, p.267-279, 1992.

[2] CIFERRI, O., TIBONI, O. The biochemistry and industrial potential of Spirulina. Annals Review Microbiology, v.39, p.503-526, 1985.

[3] COHEN, Z. Products from microalgae. In: RICHMOND, A., Handbook of Microalgal Mass Culture. Florida, USA: CRC Press, 1986,p.421-454.

[4] HANSEN, M. La Spirulina, un sorprendente suplemento dietético natural. Edaf Mexicana S/A. 76 pp., 1984.

[5] METZER, P., DEsCOUls, N., CASADO, N. Microalgal as a source of triglicerides. Comm. Eur. Communities. p.339, 1983.

[6] MÉTodos Químicos E FÍsicos PARA ANÁlise DE ALIMENTOS. Normas Analíticas do Instituto Adolfo Lutz. Instituto Adolfo Lutz. Secretaria de Estado de Saúde. SP. $1^{\text {a ed., } 1976 .}$

[7] PAoletti, C., Pushraraj, B., TOMAselli, F. L. Ricerche sulla nutrizione minerale di Spirulina platensis. ATTI XVII CONGR. NAZ. SOC. IT. MICROBIOL., Padova, 26-28 ott., v.2, p. 845-853, 1975.

[8] PAOLETTI, C., VICENZINI, M., BOCCI, F. Composizione biochimica generale delle biomasse di Spirulina platensis e Spirulina maxima. In: MATERASSI, R. (ed). Prospecttive della Ricerche. Accademia Dei Georgofili. Firenze, 20-21 nov., 1980, p.111-125.

[9] RICHMOND, A. Spirulina. In: BOROWITZKA, M.A.\& BOROWITZKA, L.J. (eds). Microalgal Biotechnology. Cambridge University Press, Cambridge, New York, 1988, p.85-121.

[10] SHIFRIN, I. S., CHISHOLM, S. W. Phytoplankton lipids : Inespecific differences and effects of nitrate, silicate and light dark cycles. T. Phycology. v.17, p.374-384, 1981.

[11] TADROS, M.Chemical composition of cyanobacteria: Spirulina maxima in response to nutrients, in bath cultures. Second International Marine Biotechnology Conference (IMBC/91), Baltimore, USA, 13-16, oct., 1991.

[12] TEDESCO, M.A., DUERR, E.O. Light, temperature and nitrogen starvation effects on the total lipid and fatty acid content and composition of Spirulina platensis 
UTEX 1928. Applied Phycology, v.1, n.3, p.201-209, 1989.

[13] TOMAselli, L., GiovannetTi, L., TORZILlo, G. Physiology of stress response in Spirulina spp. In: DOUMENGE, F.; DURAND- CHASTEL, H. \& TOULEMONT, A. (eds). Spiruline Algue de Vie. Bulletin de L'Institut Océanographique, Monaco, n.12, 1993, p.65-75.

[14] TORRES, C. G. Influência da concentração de nitrogênio na produção de lipidios e ácido gama- linolênico em Spirulina maxima. 1994. Dissertação (Mestrado), do Curso de Pós-Graduação em Ciência de Tecnologia de Alimentos, UFRRJ.

[15] ZAROUK, C. Contribution A L'etude D'une cyanophyceae. Influence de divers facteurs physiques et chimiques sur la croissance et la photosynthese de Spirulina maxima (Setch et Gardna) Geitler. 1966. PHD Thesis, University of Paris, France. 